\title{
Supporting better decisions across the nexus of water, energy and food through earth observation data: case of the Zambezi basin
}

\author{
Fortune Faith Gomo ${ }^{1}$, Christopher Macleod ${ }^{2}, J_{0 h n} \operatorname{Rowan}^{1}$, Jagadeesh Yeluripati ${ }^{2}$, and Kairsty Topp ${ }^{3}$ \\ ${ }^{1}$ Geography, School of Social Sciences, University of Dundee, Dundee, DD1 4HN, UK \\ ${ }^{2}$ The James Hutton Institute, Aberdeen, UK \\ ${ }^{3}$ Scotland's Rural College (SRUC), Edinburgh, EH9 3JG, UK
}

Correspondence: Fortune Faith Gomo (ffgomo@dundee.ac.uk)

Received: 8 June 2017 - Accepted: 25 July 2017 - Published: 1 February 2018

\begin{abstract}
The water-energy-food (WEF) nexus has been promoted in recent years as an intersectional concept designed to improve planning and regulatory decision-making across the three sectors. The production and consumption of water, energy and food resources are inextricably linked across multiple spatial scales (from the global to the local), but a common feature is competition for land which through different land management practices mediates provisioning ecosystem services. The nexus perspective seeks to understand the interlinkages and use systems-based thinking to frame management options for the present and the future. It aims to highlight advantage and minimise damaging and unsustainable outcomes through informed decisions regarding trade-offs inclusive of economic, ecological and equity considerations. Operationalizing the WEF approach is difficult because of the lack of complete data, knowledge and observability - and the nature of the challenge also depends on the scale of the investigation. Transboundary river basins are particularly challenging because whilst the basin unit defines the hydrological system this is not necessarily coincident with flows of food and energy. There are multiple national jurisdictions and geopolitical relations to consider. Land use changes have a profound influence on hydrological, agricultural, energy provisioning and regulating ecosystem services. Future policy decisions in the water, energy and food sectors could have profound effects, with different demands for land and water resources, intensifying competition for these resources in the future. In this study, we used Google Earth Engine (GEE) to analyse the land cover changes in the Zambezi river basin (1.4 million $\mathrm{km}^{2}$ ) from 1992 to 2015 using the European Space Agency annual global land cover dataset. Early results indicate transformative processes are underway with significant shifts from tree cover to cropland, with a $4.6 \%$ loss in tree cover and a $16 \%$ gain in cropland during the study period. The changes were found to be occurring mainly in the eastern (Malawi and Mozambique) and southern (Zimbabwe and southern Zambia) parts of the basin. The area under urban land uses was found to have more than doubled during the study period gearing urban centres increasingly as the foci for resource consumption. These preliminary findings are the first step in understanding the spatial and temporal interlinkages of water, energy and food by providing reliable and consistent evidence spanning the local, regional, national and whole transboundary basin scale.
\end{abstract}




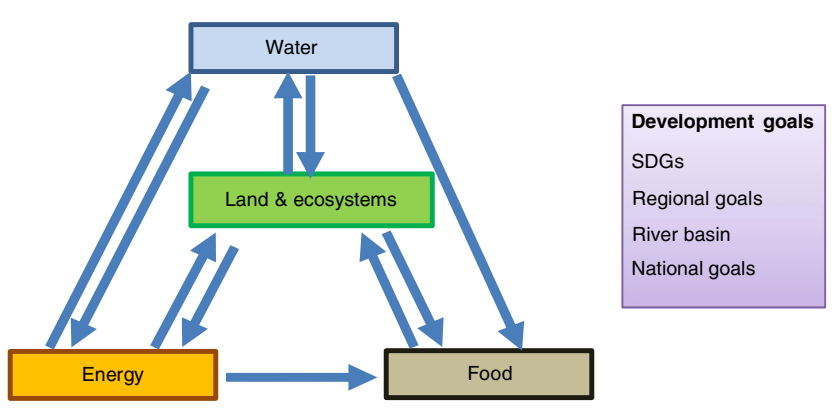

Global environmental change drivers Climate change Population growth Urbanisation

Figure 1. Illustration of linkages between WEF and Land and Ecosystems.

\section{Introduction}

Land-use and land-cover (LULC) is driven by natural and anthropogenic activities, which in turn drive changes impacting natural ecosystem (Rawat and Kumar, 2015). Understanding the patterns of land cover change and the factors driving spatial and temporal patterns is vital for proper land management and decision use of land for water resources management. There is increasing global stress on land and water resources because of population growth and increased percapita water, energy and food demand (Pfister et al., 2011). In response, the Water-Energy-Food (WEF) Nexus approach is promoted as a way of understanding the interlinkages between water, energy and food systems. For example, the Bonn 2011 Conference, "The Water Energy and Food Security Nexus - Solutions for the Green Economy" recommended that water, energy and food be considered in an integrative manner, explicitly identifying the interdependencies in decision making. This is based on the premise that decisions made in one sector affect one or more of the other sectors. Integrated decision making is therefore necessary to utilise the synergies and minimise trade-offs. In this study, it is argued water, energy and food rely on the same resource base which is land and ecosystems, and that changes in land cover affect the delivery of water, energy and food ecosystem services. Therefore, land and ecosystems is viewed to be at the centre of the WEF nexus (Fig. 1). The arrows represent the flow of resources from one sector to the other, with land and ecosystems at the centre and supporting all three sectors. Environmental change drivers, such as climate change and population growth are seen to influence decision making to achieve development goals, including Sustainable Development Goals (SDGs), regional, basin and national goals. Table 1 outlines some of the water energy and food ecosystem services associated with major land cover types.
Operationalisation of the WEF Nexus in decision making comes with a set of challenges, some of which were outlined by Eftelioglu et al. (2016) as data and modelling constraints. To understand key role of land and ecosystems for understanding and supporting WEF decision making, we need new data such as EO data and more integrated modelling (including web based information/knowledge platforms). Eftelioglu et al. (2016) argue that remote sensing in the context of WEF nexus can highlight issues within the nexus and be used to identify resource use hotspots for targeted solutions. "SubSaharan Africa has experienced long term LULC but only a few and patchy studies exist on long term characterization of LULC" (Wasige et al., 2013). In the Zambezi, land cover land use studies have also been patchy except for the Zambezi Environment Outlook (ZEO) Report (ZAMCOM, SADC, SARDC, 2015), which describes the changes in the Zambezi basin riparian countries from 2000 and 2010. The report said that there were no significant changes in land cover in the basin from 2000 to 2010.

Kamwi et al. (2015) examined the socio-economic drivers for land use and land cover changes and assessed its impacts to rural livelihoods in the Zambezi region of Namibia. They found that the land cover changes fluctuated, with years of encroachment of cropland and grassland by shrub vegetation as well as clearing of forest vegetation for crops. The authors noted that some of the changes were not permanent, hence the fluctuation. They identified the drivers of land use and land cover change as agricultural expansion, population growth, illegal logging, and increased demand for forest products and to a lesser extent government rules/policy.

Petit et al. (2001) quantified the land cover changes in South Eastern Zambia, in Lusitu area which was reported to have experienced rapid land-cover changes since the resettlement of 6000 people in 1958 because of Kariba dam construction and subsequent filling in 1958. The population of the area rose from around 750 inhabitants pre-Kariba dam, to 8096 in 1963 and by 1994 it had doubled. Since 1958 agriculture has rapidly expanded, increasing bare land situation and increased land degradation. Livestock population also increased from 562 in 1959 to 26800 in 1991, leading to situations of overgrazing and loss of livestock in times of drought. The authors found that $44 \%$ of the area has been affected by land cover changes with trends towards increasing bare soil and cultivated areas, and rapid decrease in forest and natural vegetation cover. They recorded an average annual rate of change of $4 \%$ with agricultural expansion as the dominant change process. With most of the basin countries having policies geared towards water resources, energy and agricultural development (World Bank, 2010), it is important to understand historical land cover change and land use patterns, to understand spatial interactions. Thus, spatially explicit assessment of water energy and food system/sector interactions is required to identify extent and locations of change (Prestele et al., 2016). This paper is a first step to understand long term land cover change trends in the Zam- 
Table 1. Water-energy-food ecosystem services associated with land cover types.

\begin{tabular}{|c|c|c|c|}
\hline Land Cover/Land Use & Water & Energy & Food \\
\hline $\begin{array}{l}\text { Cropping and } \\
\text { herbaceous cover }\end{array}$ & $\begin{array}{l}\text { Water Demand } \\
\text { Green water demand } \\
\text { Irrigation water } \\
\text { Livestock water use }\end{array}$ & Biofuels production & Food production \\
\hline Forests & $\begin{array}{l}\text { Flow regulation } \\
\text { Groundwater recharge } \\
\text { Climate regulation }\end{array}$ & $\begin{array}{l}\text { Fuel wood (firewood and } \\
\text { charcoal) } \\
\text { Carbon sequestration }\end{array}$ & Game \\
\hline $\begin{array}{l}\text { Shrub land, grassland and } \\
\text { sparse vegetation }\end{array}$ & $\begin{array}{l}\text { Flow regulation } \\
\text { Climate regulation } \\
\text { (lesser extent than forests) }\end{array}$ & & $\begin{array}{l}\text { Livestock production } \\
\text { Nutrient circulation in soil }\end{array}$ \\
\hline Urban/built up areas & $\begin{array}{l}\text { Urban water supply } \\
\text { Industrial water demand } \\
\text { Waste water production }\end{array}$ & $\begin{array}{l}\text { Domestic energy consump- } \\
\text { tion } \\
\text { Industrial energy consumption }\end{array}$ & $\begin{array}{l}\text { Urban food demand/consumption } \\
\text { (urban farming) }\end{array}$ \\
\hline $\begin{array}{l}\text { Wetlands and Water } \\
\text { bodies }\end{array}$ & $\begin{array}{l}\text { Hydrological regulation/ } \\
\text { Flood control } \\
\text { Surface water supply } \\
\text { Groundwater recharge Water demand } \\
\text { Environmental flow requirements } \\
\text { Public water use }\end{array}$ & $\begin{array}{l}\text { Hydropower production } \\
\text { Cooling water }\end{array}$ & $\begin{array}{l}\text { Flood recession agriculture } \\
\text { Irrigation water } \\
\text { Livestock water use } \\
\text { Fisheries }\end{array}$ \\
\hline
\end{tabular}

bezi river basin. The objectives of the study are to assess the changes in land cover in the Zambezi river basin from 1992 to 2015 , and to determine the extent of change in cropping systems, forests, urban areas and water bodies. There is a general lack of consistent coverage of satellite data for such large areas, and unavailability of training and validation data for creating land cover maps using raw data, as well as a need for high performance computing (Giri et al., 2013). As a result, there are difficulties in preparing image mosaics and making sure that the multitemporal land cover maps produced for comparison are appropriate for the task (Giri et al., 2013; Vittek et al., 2014). The use of global land cover products allows for the monitoring and analysis of land cover globally and over large areas. It removes the need to work with and process raw satellite images, which would involve volumes of remotely sensed data for such large areas, and deals with problems of data gaps in satellite imagery (Maynard et al., 2016). It is acknowledged here that such data may have limitations, particularly that land cover classification at high resolution may provide limited insight into real land cover dynamics at local scales, and that it can provide preliminary identification of historical and ongoing changes (Tropek et al., 2014).

\section{Study area}

The study is carried out for the Zambezi River basin. The Zambezi basin covers an area of 1.39 million $\mathrm{km}^{2}$, the fourth largest in Africa and is one of the most diverse and valuable natural resources in Africa (World Bank, 2010). The basin is transboundary, spanning over 8 countries in Southern Africa, namely Angola, Botswana, Malawi, Mozambique, Namibia, Tanzania, Zambia and Zimbabwe. The basin is home to an estimated population of 32 million people. Figure 2 shows the map of the Zambezi, its sub basins and the riparian countries.

\section{Materials and methods}

The Climate Change Initiative (CCI) team of the European Space Agency (ESA) officially released the first time series of annual global land cover maps at $300 \mathrm{~m}$ resolution, spanning a 24-year period, from 1992 to 2015 in April 2017 (ESA, 2017). The global land cover dataset covers the longest period available to date (ESA, 2017). This highresolution imagery is considered sufficient to identify areas of land cover change, and estimate changes in the extent (area) for each land cover type in the Zambezi river basin over the 24-year period. More detailed and finer resolution land cover monitoring studies can then be carried out for identified areas of interest. Land cover changes was analysed for the period from 1992 to 2015 to record and assess the major land cover trends in the basin, using Google Earth Engine and ArcGIS 10.5. The ESA/CCI global land cover products used in this study were produced by reprocessing of the full archives of 5 different satellite missions providing daily observation of the Earth, including NOAAAVHRR HRPT, SPOTVegetation, ENVISAT-MERIS FR and RR, ENVISAT-ASAR, and PROBA-V for the most recent years (ESA, 2017). The land cover changes in the Zambezi 


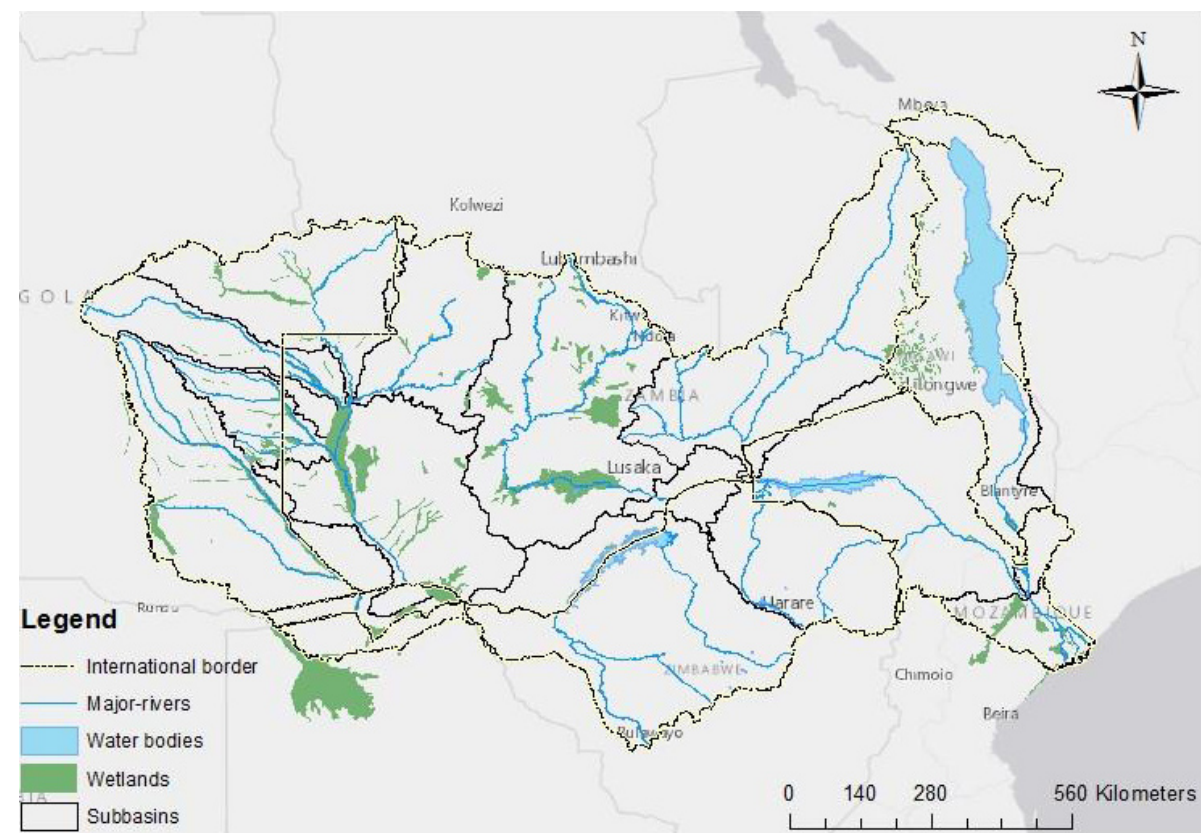

Figure 2. Zambezi Basin Map.

river basin are analysed using Google Earth Engine (GEE) and ArcGIS 10.5. GEE is a web based catalogue of satellite imagery and geospatial datasets with planetary-scale analysis capabilities (https://earthengine.google.com/).

To create a land cover change map, the Zambezi land cover map of 1992 was subtracted from that of 2015. This produced a change vector map with pixels having a spectral reflectance value of the difference between 2015 and 1992. This map showed areas of changed, but even areas of the slightest change showed up on the difference map. The result was squared, and the limit of the spectral variation set at 1000. This meant small differences in the change vector showed up as no change (black) on the map, and those with a squared variation of above 1000 showed up as areas of change (white). In this study, areas of land cover change were defined as those with the square of surface reflectance variation of more than 1000 .

Arc GIS 10.5 was then used to quantify the changes in land cover in the basin. Out of the 22 predefined ESA/CCI land cover classes 20 were represented in the Zambezi basin. The Zambezi basin land cover was re-classified into 7 broad classes to represent cropland and herbaceous cover; tree cover; mosaic cropland and natural vegetation; shrub, grassland and sparse vegetation; bare areas; urban areas; and wetlands and water bodies. The areas covered by each of the classes was then calculated from 1992 to 2015. Percentage changes for each broad class were calculated from 1993 to 2015, as follows:

$\%$ change $=\left(\frac{\text { Area } t_{1}-\text { Area } t_{2}}{\text { Area } t_{1}}\right) \times 100$
Trend analysis was also carried out for the 7 broad classes to see when the land cover changes occurred and the pattern of change over the study period.

\section{Results and discussion}

\subsection{Land cover changes}

There has been progressive clearing of forest areas (green), and expansion of agricultural areas (yellow) since 1992 through 2004 to 2015 . This can be seen by simple visual inspection and comparison of the Zambezi land cover maps shown in Fig. 4a and c. These observations are consistent with the findings of Kamwi et al. (2015) who found agricultural activities as the main driver of land cover change in Namibia, and Petit et al. (2001) who found that there were increasing cultivated areas and bare areas in south eastern Zambia from 1986 to 1997 . Figure 4d shows the squared change vector map for the Zambezi basin. The black areas show no change while white represents areas where the land cover changed from 1992 to 2015. Figure 4d shows that most noticeable changes occurred in the eastern and southern parts of the basin, with some localized changes in the centre of the basin. Referring to Fig. 4, in the East is Malawi and Mozambique, and in the south, is Zimbabwe and part of Zambia. In the centre of the basin (Zambia) lies some wetlands, and these are also shown to be areas of significant changes in the period 1992 to 2015. 


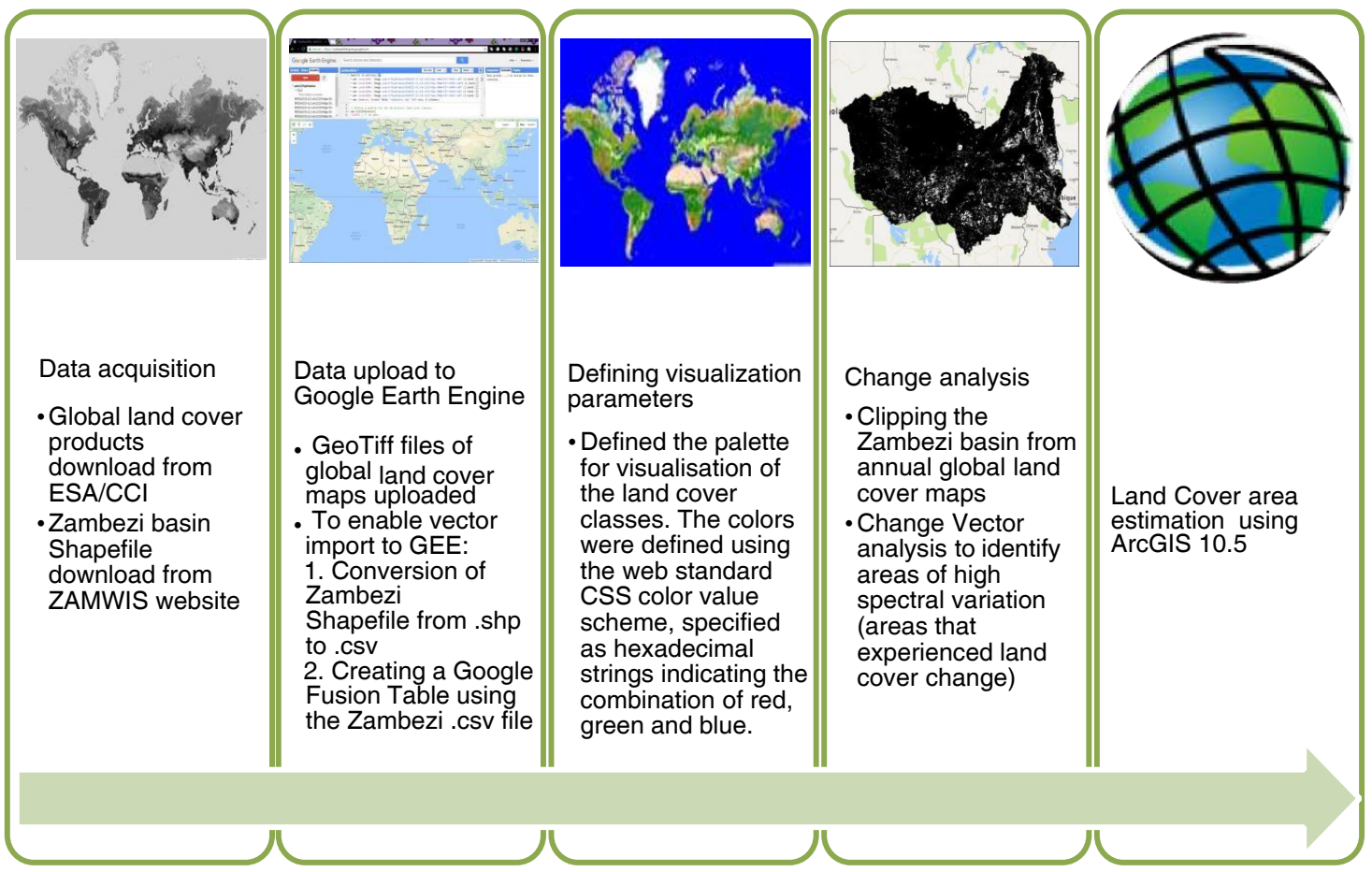

Figure 3. Methodological steps.

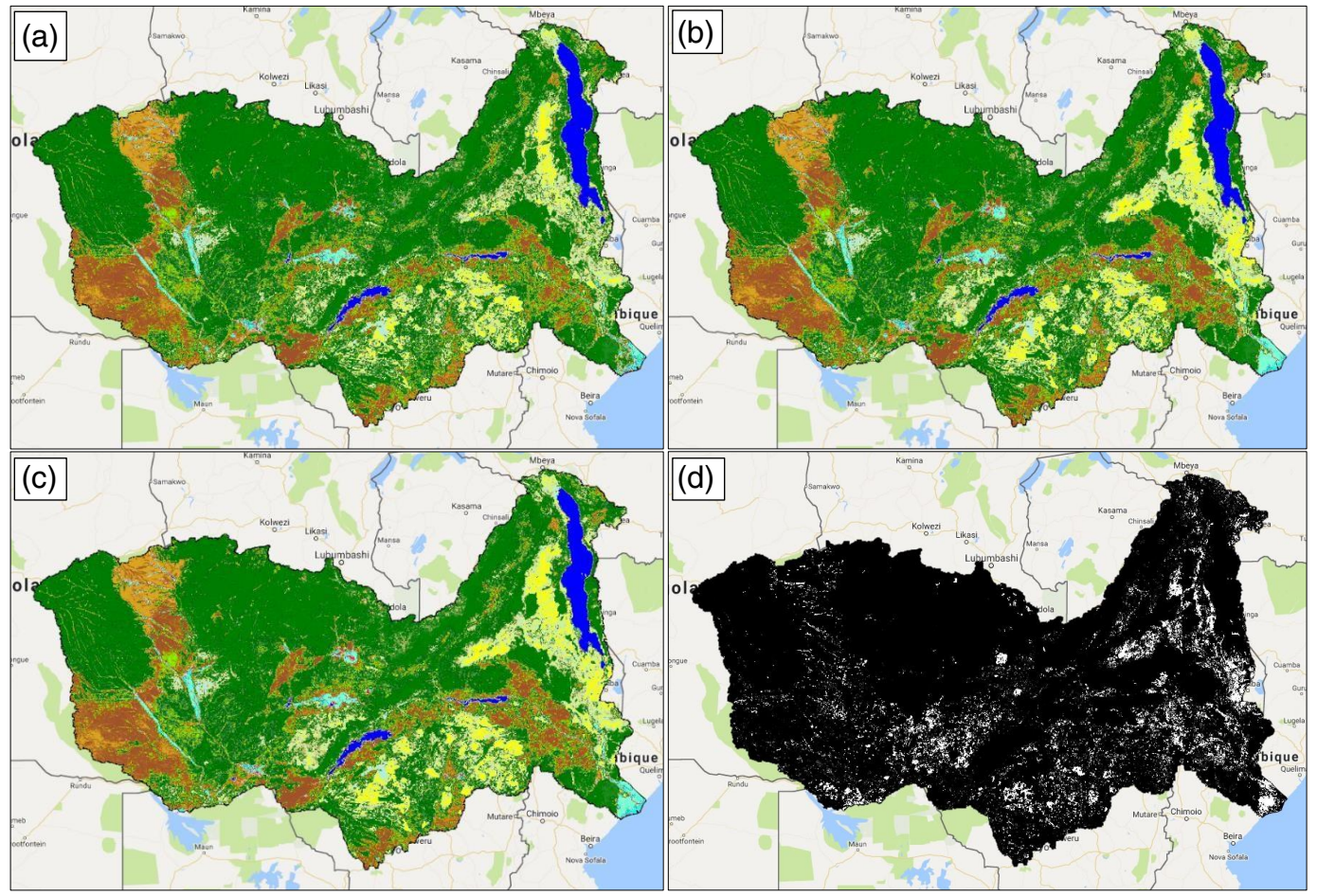

Figure 4. Zambezi land cover maps for 1992 and 2015, and land cover difference map showing areas of land cover change for this period (a Zambezi Land Cover 1992; b Zambezi land cover 2004; c Zambezi land cover 2015; d Zambezi squared difference (2015-1992)). 


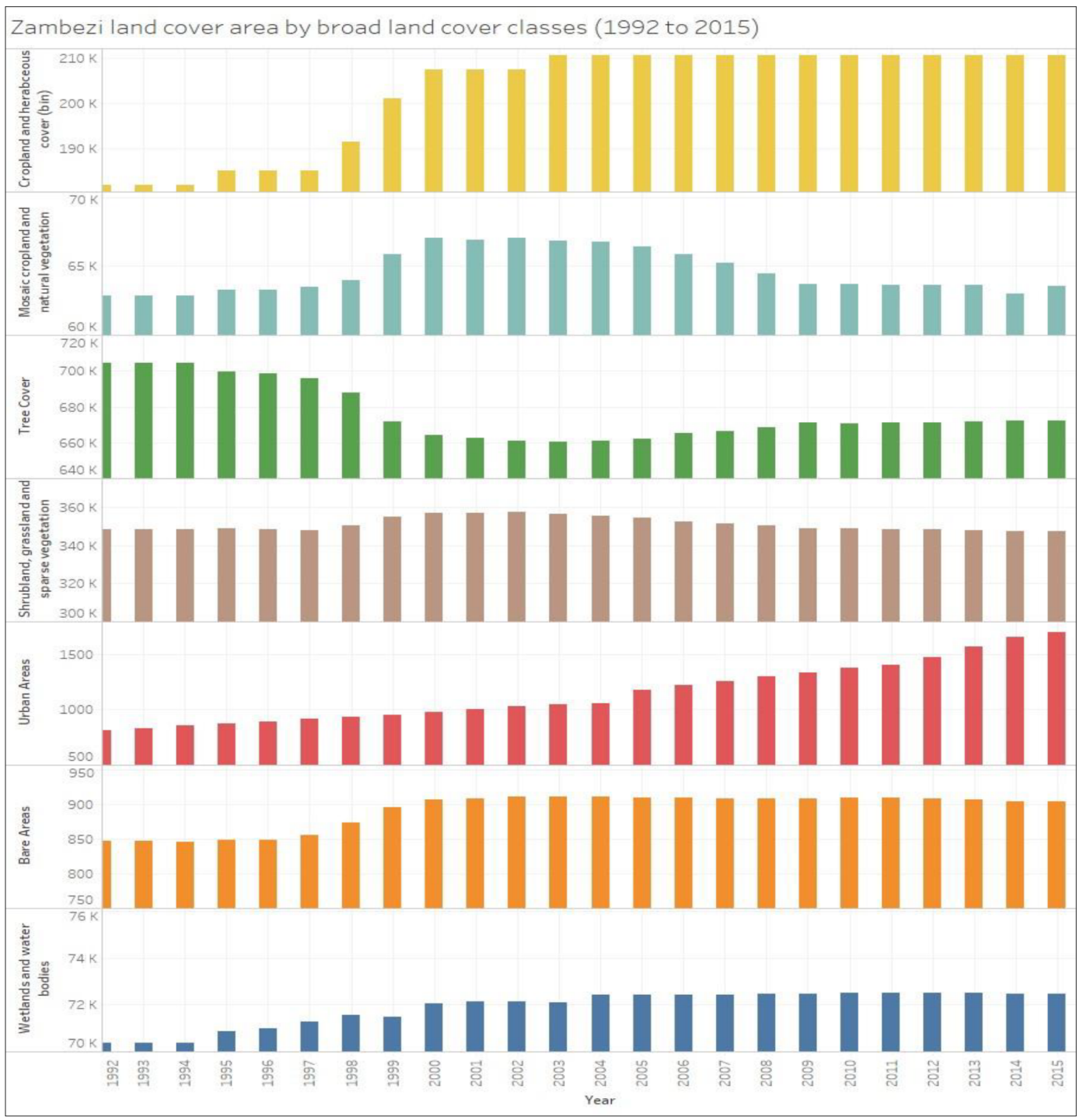

Figure 5. Changes in land cover area (in square kilometres) in the Zambezi river basin.

\subsection{Land cover change extent}

Having reclassified the land cover into 7 broad classes, the area for each broad class was calculated. Figure 5 shows that the most noticeable changes occurred in forest cover and cropland areas, showing a transformation of tree cover to cropland. Table 2 summarises the percentage changes and shows that cropland area in the Zambezi grew by $15.98 \%$ and covered $15.43 \%$ of the basin area in 2015, while tree cover was lost by $4.57 \%$ between 1992 and 2015. Mosaic of tree cover and cropland increased slightly by $1.1 \%$ and bare areas by $6.78 \%$, while urban areas more than doubled during the 24 years of study. As much as $3057 \mathrm{~km}^{2}$ lost for tree cover was not taken up by cropland. This land area may have been taken up by other land cover types that gained, i.e. urban areas, bare areas, mosaics of cropland and natural vegetation. This indicates that trees were not only cleared to make way for cropland, but other land uses too, that may have a bearing on the provision of water, energy and food.

\subsection{Land cover change trends}

Figure 5 shows the land cover area for the broad classes each year from 1992 to 2015 . There was a near exponential increase in cropland from the year 1993 to 2002/3 from at which time the cropland area did not change until 2015.

The pattern of increase in cropland area matches that of the decrease in tree cover area, suggesting that forest areas were cleared to make way for cropland. A similar pattern is noticeable with the mosaic of cropland and natural vegetation, suggesting that the cover transitioned from tree cover to mixed cropland and natural vegetation to cropland. From the year 2006, the mosaic of cropland and natural vegetation area starts to decrease, and this is matched with an in- 
Table 2. Percentage changes in land cover from 1992 to 2015.

\begin{tabular}{lrr}
\hline Land Cover Type & \% change $1992-2015$ & \% of basin area in 2015 \\
\hline Cropland and herbaceous cover & $15.98 \%$ & $15.43 \%$ \\
Tree Cover & $-4.57 \%$ & $49.07 \%$ \\
Mosaic cropland and natural vegetation & $1.10 \%$ & $4.64 \%$ \\
Shrubland, grassland and sparse vegetation & $-0.19 \%$ & $25.38 \%$ \\
Bare areas & $6.78 \%$ & $0.07 \%$ \\
Urban areas & $108.66 \%$ & $0.12 \%$ \\
Wetlands and water Bodies & $2.95 \%$ & $5.29 \%$ \\
\hline
\end{tabular}

Annual percentage land cover changes



Figure 6. Annual \% land cover changes in the Zambezi for the 7 broad classes.

crease in tree cover in the same year, and for the years after, suggesting a regeneration of some of the tree cover that had been cleared earlier for cropland. Urban areas show continued growth throughout the study period, indicating urban expansion in the basin

during the study period. Wetlands and water bodies increased their cover in the early years of the study period, and stayed almost the same from the year 2000 to 2015. Figure 6 shows annual \% land cover changes in the Zambezi for the 7 broad classes. Cropland area had the highest annual increase in $1999(5.17 \%)$, after which the annual changes were below $2 \%$, and negative in some years up to 2015. In the same year that cropland had the highest increase, tree cover had the highest decrease $(2.39 \%)$. Urban areas, expanded by more than double during the study period. There has been a year on year increase of above $2 \%$ in most years of urban areas in the basin, with 50 the highest increase was in 2005 at $11.80 \%$.

\section{Conclusion and discussion}

During the period from 1992 to 2015, land cover changes in the Zambezi basin have been mainly occurring in the eastern (Malawi and Mozambique) and southern (Zimbabwe and Zambia) parts of the basin, with some localized changes in the centre (Zambia) of the basin. The localised changes in the centre of the basin were determined to be occurring in wetland areas, where there is loss of wetland vegetation cover.

In the 24-year period of study, there was a gain in cropland area by $15.98 \%$ and a loss of tree cover of $4.57 \%$. The land area lost in forest cover almost equals the land area gained in cropland, with a difference of $3057 \mathrm{~km}^{2}$ in land area lost and gained in tree cover and cropland, showing that there is transformation of tree cover to cropland in the basin. This difference could be accounted for clearing of forests for wood fuel as biomass derived energy is the biggest source of energy and accounts for $74 \%$ of energy in the Zambezi basin, and used by most the Zambezi basin population (ZAMCOM, SADC, SARDC, 2015). Land cover change trend analysis showed that cropland increased and the mosaic of cropland 
and natural vegetation increased in a pattern similar to that of the decrease of tree cover in the first half of the study period. This shows that there was an expansion of agricultural area during this period, and that there has been no agricultural expansion in the basin during the second half of the study period. This finding is in line with the Zambezi Environment Outlook of 2015, which reported no major changes in cropland from 2000 to 2010 . On the other hand, urban areas were found to be the most dynamic land cover type in the basin, increasing steadily throughout the study period, and increasing by more than $100 \%$ since 1992 . Identifying and understanding these changes to the basin is vital for informing policy makers, managers and stakeholders about what actions can be taken to better manage land resources to maintain the ecosystem services supporting the WEF nexus effectively. It is important to note that these data are aggregated over a large river basin. The changes recorded here are happening in specific and more localised areas, and it may be worth studying these changes at localised scales at a finer resolution to understand more of the land cover land use dynamics occurring at in these areas.

\section{Further work}

This paper is a first step to the study of the water, energy and food nexus challenges in the Zambezi river basin. The overall study aims to support decision making in water, energy and food sectors in the basin, by illuminating and clarifying the interlinkages between these sectors, as well as land resources. It is envisaged that this will enable policy and decision makers in the basin to take advantage of the synergies that may be revealed through this study, and minimise tradeoffs among these sectors, thereby making more sustainable decisions to achieve sustainable development goals for water, energy and food. As the Zambezi river basin is vast, a detailed study of this nature for the whole basin would require a bigger research team and more resources. So, as a starting point, this paper identifies resource use hotspots to facilitate a choice of study area within the basin for a more detailed study of the WEF nexus, and how this approach can improve decision making across the WEF sectors.

Code availability. Link to JavaScript code used in GEE for this study: https://code.earthengine.google.com/ 98a21319dc5b6b22a2c247b4f099ce20. One needs a Google account and Google Earth Engine account to access.

Data availability. Link to ESA Global Land Cover products: http: //maps.elie.ucl.ac.be/CCI/viewer/.

Author contributions. This paper is part of a $\mathrm{PhD}$ study. FFG is the PhD student and therefore the first author. CJAM, JSR, JY, and CFET are the PhD supervisory team and provide technical and editorial support.

Competing interests. The authors declare that they have no conflict of interest.

Disclaimer. The views and opinions expressed in this article are those of the authors and do not necessarily reflect the official policy or position of project funders, the Scottish Government and the HydroNation Programme. This article is a product of academic research.

Special issue statement. This article is part of the special issue "Water security and the food-water-energy nexus: drivers, responses and feedbacks at local to global scales". It is a result of the IAHS Scientific Assembly 2017, Port Elizabeth, South Africa, 10-14 July 2017.

Acknowledgements. This paper is part of a $\mathrm{PhD}$ project funded by the Scottish Government through HydroNation Scholars Programme 2015 (grant code 064272.S002). The authors would also like to thank Mark Cutler for his helpful discussions.

Edited by: Barry Croke

Reviewed by: Lauren Bulcock and one anonymous referee

\section{References}

Eftelioglu, E., Jiang, Z., Ali, R., and Shekhar, S.: Spatial computing perspective on food energy and water nexus, J. Environ. Stud. Sci., 56, 62-76, 2016.

European Space Agency: $300 \mathrm{~m}$ annual global land cover time series from 1992 to 2015, Climate Change Initiative Land Cover Newsletter, Issue n. 7 April 2017, Retrieved on 10 April 2017 from https://www.esa-landcover-cci.org/?q=webfm_send/ 88, last access: 1 September 2017.

Giri, C., Pengrab, B., Longc, J., and Lovelanda, T. R.: Next generation of global land cover characterization, mapping, and monitoring, Int. J. Appl. Earth Obs., 25, 30-37, https://doi.org/10.1016/j.jag.2013.03.005, 2013.

Kamwi, J. M., Chirwa, P. W. C., Manda, S. O. M., Graz, P. F., and Kätsch, C.: Livelihoods, land use and land cover change in the Zambezi Region, Namibia, Popul. Environ., 37, 207-230, 2015.

Maynard, J. J., Karl, J. W., and Browning, D. M.: Effect of spatial image support in detecting long-term vegetation change from satellite time-series, Landscape Ecol., 31, 2045, https://doi.org/10.1007/s10980-016-0381-y, 2016.

Petit, C., Scudder, T., and Lambin, E.: Quantifying processes of land-cover change by remote sensing: Resettlement and rapid land-cover changes in southeastern Zambia, Int. J. Remote Sens., 22, 3435-3456, https://doi.org/10.1080/01431160010006881, 2001.

Pfister, S., Bayer, P., Koehler, A., and Hellweg, S.: Environmental impacts of water use in global crop production: Hotspots and 
trade-offs with land use, Environmental Science and Technology, 45, 5761-5768, 2011.

Prestele, R., Alexander, P., Rounsevell, M. D. A., Arneth, A., Calvin, K., Doelman, J., Eitelberg, D. A., Engström, K., Fujimori, S., Hasegawa, T., Havlik, P., Humpenöder, F., Jain, A. K., Krisztin, T., Kyle, P., Meiyappan, P., Popp, A., Sands, R. D., Schaldach, R., Schüngel, J., Stehfest, E., Tabeau, A., Van Meijl, H., Van Vliet, J., and Verburg, P. H.: Hotspots of uncertainty in land-use and landcover change projections: a global-scale model comparison, Glob. Change Biol., 22, 3967-3983, 2016.

Rawat, J. S. and Kumar, M.: Monitoring land use/cover change using remote sensing and GIS techniques: A case study of Hawalbagh block, district Almora, Uttarakhand, India, The Egyptian Journal of Remote Sensing and Space Science, 18, 77-84, 2015.

Tropek, R., Sedláček, O., Beck, J., Keil, P., Musilová, Z., Šímová, I., and Storch, D.: Comment on "High-resolution global maps of 21st-century forest cover change", Science, 344, 6187, https://doi.org/10.1126/science.1248753, 2014.
Vittek, M., Brink, A., Donnay, F., Simonetti, D., and Desclée, B.: Land Cover Change Monitoring Using Landsat MSS/TM Satellite Image Data over West Africa between 1975 and 1990, Remote Sensing, 2014, 658-676, https://doi.org/10.3390/rs6010658, 2014.

Wasige, J. E., Groen, T. A., Eric, S., and Victor, J.: Monitoring basin-scale land cover changes in Kagera basin of lake Victoria using ancillary data and remote sensing, Int. J. Appl. Earth Obs., 21, 32-42, https://doi.org/10.1016/j.jag.2012.08.005, 2013.

World Bank: Summary report, Washington, DC, World Bank, http: //documents.worldbank.org/curated/en/724861468009989838/ Summary-report (last access: 1 September 2017), 2010.

ZAMCOM, SADC, SARDC: Zambezi Environment Outlook 2015, ZAMCOM, SADC,SARDC, Harare, Zimbabwe, Gaborone, Botswana, 2015. 